\title{
The Risk Factors of Periventricular Leukomalacia among Very Low Birth Weight Infants
}

\author{
Hyun A Park, MD and Jong Hee Hwang, MD, PhD \\ Department of Pediatrics, Inje University Ilsan Paik Hospital, Inje University College of Medicine, Goyang, Korea
}

\section{ABSTRACT}

Purpose: Periventricular leukomalacia (PVL) is an important morbidity in preterm infants. Its reported prevalence in very low birth weight (VLBW) infants is $3 \%$ to $15 \%$ in VLBW infants. PVL develop seizure disorder, intellectual disability, visual problem, and cerebral palsy. This study was done to describe the risk factors of PVL in VLBW infants.

Methods: Medical records of 172 VLBW infants at Inje University Ilsan Paik Hospital neonatal intensive care unit were reviewed retrospectively from January 2010 to December 2014. Patients were divided into the non-PVL group $(n=155)$ and the PVL group ( $\mathrm{n}=17)$. The PVL group included both cystic and non-cystic forms. Demographic findings and factors associated with PVL were compared between these groups.

Results: The incidence of non-cystic and cystic PVL was 9.8\%. The mean gestational age was significantly lower in the PVL group. The mean birth weight was not significantly different between the groups. The incidences of premature rupture of membrane and pregnancy induced hypertension were not significantly different between the two groups. The number of histologic chorioamnionitis was significantly higher in the PVL group $(P<0.05)$. Other conditions such as respiratory distress syndrome, patent ductus arteriosus, early-onset sepsis, and hypotension were not significantly different between the two groups. The incidence of intravascular hemorrhage (IVH) (grade $\geq 3$ ) was more significant in the PVL group $(P<0.05)$. Multiple logistic regression analysis indicated that histologic chorioamnionitis (odds ratio [OR], 6.3; 95\% confidence interval [CI], 1.1 to 36.3) and IVH (grade $\geq 3$ ) (OR, 16.9; 95\% CI, 1.9 to 153.1) were significant risk factors of PVL.

Conclusion: Histologic chorioamnionitis and IVH (grade $\geq 3$ ) increase the risk of PVL in VLBW infants. Strategies to prevent these conditions could attenuate the incidence of PVL.

Key Words: Leukomalacia; Periventricular; Infants, premature

\section{서론}

미숙아나 고위험 신생아에 대한 집중치료의 발전으로 국내 출생체중 $1,500 \mathrm{~g}$ 미만의 극소 저체중출생아(very low birth weight infants)의 생존율이 향상되면서 신생아분과 전문의들은
Received: 15 October 2018

Revised: 27 February 2020

Accepted: 3 March 2020

Correspondence to: Jong Hee Hwang, $\mathrm{MD}, \mathrm{PhD}$

Department of Pediatrics, Inje University Ilsan Paik Hospital, Inje University College of Medicine, 170 Juhwa-ro, Ilsanseo-gu, Goyang 10380, Korea

Tel: +82-31-910-7583

Fax: +82-31-910-7108

E-mail: jhhwang@paik.ac.kr

Copyright(c)

By Korean Society of Neonatology.

All right reserved.

This is an Open-Access article distributed under the terms of the Creative Commons At tribution Non-Commercial License (http:// creativecommons.org/licenses/by-nc/4.0), which permits unrestricted non-commercial use, distribution, and reproduction in any medium, provided the original work is properly cited. 
이들의 생애 주기(life span) 동안 정상적인 발달 단계를 따라가고 사회적으로 잘 적응할 수 있도록 출생 전과 출생 후 신생아 집중치 료실(neonatal intensive care unit, NICU)에서 입원 치료를 하는 기 간뿐만 아니라 퇴원 후에도 나타날 수 있는 불량한 이환과 장기적 인 합병증을 예방하고자 지속적인 노력과 연구를 하고 있다. 그럼 에도 불구하고 주산기적 요인, 태아의 요인, 그리고 출생 후 요인 등 다양한 원인에 의해서 극소 저체중출생아 특히, 초극소 저체중 출생아(extremely low birth weight infants)의 중증 뇌실 내 출혈 (intravascular hemorrhage)과 뇌실 주위 백질연화증(periventricular leukomalacia, PVL)의 발생 빈도는 크게 감소하고 있지 못한 상태이 다.

PVL은 극소 저체중출생아의 3\%-15\%에서 발생하며 ${ }^{1,2)}$ 중증의 $\mathrm{PVL}$ 의 발생은 사망을 초래하거나 뇌성마비, 경련성 질환, 인지 및 학습장애 등의 신경학적인 합병증을 유발하게 된다. PVL의 위험인 자로는 미숙아, 태반 기능 부전, 융모양막염, 조발형 패혈증, 저산소 증, 중증의 저혈압, 뇌실 내 출혈, 동맥관 개존 등이 보고되어 있는데 ${ }^{3-9}$, 최근 신생아 집중치료의 발전으로 극소 저체중출생아의 생존율 이 향상되고 있는 상황에서 단일기관에서의 극소 저체중출생아를 대상으로 PVL을 유발하는 위험인자를 알아보고 이를 예방할 수 있 는 방법을 모색하고자 한다.

\section{대상 및 방법}

2010년 1월부터 2014년 12월까지 인제대학교 일산백병원 NICU 에 입원한 출생체중 $1,500 \mathrm{~g}$ 미만의 극소 저체중출생아 210 명 중 뇌 초음파 또는 뇌 자기공명영상촬영(magnetic resonance imaging, $\mathrm{MRI)}$ 을 시행하기 전에 사망하거나 전원을 간 경우, 그리고 심한 선 천성 기형을 가진 28 명을 제외한 172 명을 대상으로 PVL의 발생 빈 도와 위험인자에 대해서 조사하였다. PVL은 De Vries 등긔의 진단 기 준에 의하여 뇌 초음파 또는 뇌 MRI 검사에서 뇌실 주위에 음영이 1 주일 이상 증가된 경우 1 단계, 뇌실 주위의 증가된 음영이 작은 낭종 으로 변화된 경우 2 단계, 뇌실 주위 낭종성 변화가 전두정엽에서 후 두엽까지 확장되는 경우 3 단계, 뇌실 주위 낭종성 변화가 뇌회질하 백질 부위로 확장되는 경우 4단계로 정의 하였담). 영상의학과 전문 의에 의해 출생 후 1 주 이내에 첫 뇌 초음파검사를 시행하였고, 이후 1-2주 간격으로 추적검사가 진행되었으며 퇴원 전에는 뇌 MRI 검사 를 시행하였다. 본 연구에서 1 단계의 비낭종성 뇌실 주위 백질연화 증(non-cystic PVL)의 진단은 영상의학과 전문의의 판독과 재활의 학과 전문의의 협진을 통하여 입원 기간과 외래 진료에서 신경학적 뇌 손상이 명백하게 나타나 재활치료가 지속적으로 필요한 경우로 제한하였다. 대상 환아는 PVL이 있었던 군(PVL군)과 PVL이 없었던 군(non-PVL군)으로 나누어 분류한 후, 의무기록지를 토대로 후향적
인 연구를 진행하였다.

인구학적 특징으로 재태주령, 출생체중, 아프가 점수, 분만 형태, 성별 등을 비교하였으며 주산기 인자로써 임신성 고혈압, 임신성 당 뇨, 조기 양막 파수, 양막 파수 기간, 산모의 항생제 사용 여부, 산모 의 항생제 사용 기간, 조직학적 융모양막염, 양수 과소증, 산전 스테 로이드 투여 등을 조사하였다. 출산 후 인자로써 신생아 호흡곤란 증후군, 동맥관 개존증, 지속성 폐 고혈압증, 폐 기흥, 기계적 환기 요법, 산소 투여 기간, 배꼽 혈관 도관을 포함한 중심 정맥 도관 사용 기간, 조발형을 포함한 패혈증의 유무, 패혈증의 발생 시기, 저혈압, 괴사성 장염 등을 비교하였고 이환율과 관련하여 기관지폐 형성 이 상, 3 단계 이상의 중증의 뇌실 내 출혈, 미숙아 망막증의 발생과 치 료 여부, 사망률, 입원 기간 등을 비교하였다.

통계적 처리는 SPSS version 21.0 (IBM Corp., Armonk, NY, USA) 을 사용하여 군 간의 인자들을 비교 분석하였다. 비모수적 검정 방 법으로 범주형 변수는 Fisher's exact test, 연속형 변수는 KruskalWallis test를 이용하였으며 PVL의 위험인자에 대해서는 재태주령, 출생체중, 조직학적 융모양막염, 조발형 패혈증, 3 단계 이상의 중 증의 뇌실 내 출혈, 동맥관 개존, 저혈압 등 기존에 위험인자로 알려 진 인자들과 단변량 분석에서 통계적으로 유의한 결과가 나타난 인 자들을 모두 보정하여 다변량 로티스틱 회귀분석(multiple logistic regression)을 통해 조사하였다. 유의 수준은 $P<0.05$ 로 하였으며, 관찰값은 평균ㅍ표준편차로 제시하였다.

\section{결과}

\section{1. 발생 빈도 및 인구학적 특징}

172 명의 극소 저체중출생아 중 non-cystic PVL 및 낭종성 뇌실 주 Table 1. Characteristics in Very Low Birth Weight Infants with PVL

\begin{tabular}{lccc}
\hline Characteristic & $\begin{array}{c}\text { Gestational } \\
\text { age (wk) }\end{array}$ & $\begin{array}{c}\text { Birth } \\
\text { weight (g) }\end{array}$ & $\begin{array}{c}\text { IVH } \\
\text { grade } \geq 3\end{array}$ \\
\hline Grade of PVL & $25.5 \pm 2.6$ & $843 \pm 79$ & 0 \\
$1(\mathrm{n}=4)$ & $25.5 \pm 1.6$ & $896 \pm 270$ & 3 \\
$2(\mathrm{n}=6)$ & $26.0 \pm 1.8$ & $945 \pm 305$ & 2 \\
$3(\mathrm{n}=6)$ & $30^{+1}$ & 1,220 & 0 \\
$4(\mathrm{n}=1)$ & $34.3 \pm 42.2$ & & \\
Diagnosis of first cysts (d) & $(6-152)$ & & \\
& $7.6 \pm 5.7$ & & \\
Diagnosis of IVH grade $\geq 3$ (d) & $(3-17)$ & &
\end{tabular}

Values are expressed as mean \pm standard deviation or mean \pm standard deviation (range).

Abbreviations: PVL, periventricular leukomalacia; IVH, intraventricular hemorrhage. 
위 백질연화증(cystic PVL)으로 진단된 경우는 17 명으로 $9.8 \%$ 의 빈도 를 나타냈으며 이 중 1단계인 non-cystic PVL은 4명으로 PVL로 진단 된 경우의 23.5\% (4/17)를 차지했고 2단계는 6명, 3단계는 6명, 4단 계는 1 명이었다. Non-cystic PVL이 발생한 환아는 모두 초극소 저체 중출생아였고 첫 진단은 뇌 초음파검사로 진행되었고 퇴원 전에 뇌

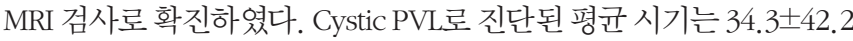
일로 빠르게는 생후 6일째 진단되었다. 1단계의 non-cystic PVL은 음 영 증가가 1 주일 이상 지속되어야 하고 최종적으로 퇴원 직전 뇌 MRI 검사로 확진을 했기 때문에 진단 시기는 평가하지 않았다. 3단계 이

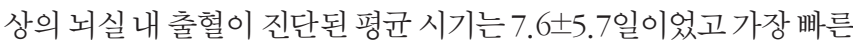
진단 시기는 생후 3 일이었다(Table 1). 평균 재태주령은 PVL이 발생

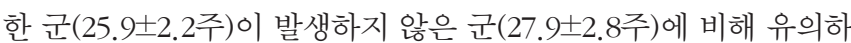
게 작았고 $(P<0.05)$, 평균 출생체중은 두 군 간에 통계적인 차이는 없

Table 2. Demographic Characteristics in Very Low Birth Weight Infants

\begin{tabular}{lccc} 
Characteristic & PVL $(\mathrm{n}=17)$ & Non-PVL $(\mathrm{n}=155)$ & $P$-value \\
\hline Gestational age (wk) & $\begin{array}{r}25.9 \pm 2.2 \\
\left(23^{+2}-31^{+2}\right)\end{array}$ & $\begin{array}{c}27.9 \pm 2.8 \\
\left(23^{+6}-33^{+4}\right)\end{array}$ & 0.007 \\
& $949 \pm 247$ & $1,068 \pm 284$ & 0.099 \\
Birth weight (g) & $(580-1,400)$ & $(420-1,490)$ & \\
& & & \\
Apgar score & $4.3 \pm 1.9$ & $4.5 \pm 2.1$ & 0.673 \\
$\quad 1$ min & $7.1 \pm 0.9$ & $7.1 \pm 1.4$ & 0.937 \\
5 min & $11(65)$ & $78(50)$ & 0.312 \\
Male sex & $17(100)$ & $153(99)$ & 1.000 \\
Inborn & $13(76)$ & $114(74)$ & 1.000
\end{tabular}

Values are expressed as mean \pm standard deviation (range), mean \pm standard deviation, or number (\%).

Abbreviation: PVL, periventricular leukomalacia.

Table 3. Prenatal Associated Factors of PVL in Very Low Birth Weight Infants

$\begin{array}{lccc}\text { Variable } & \begin{array}{c}\text { PVL } \\ (\mathrm{n}=17)\end{array} & \begin{array}{c}\text { Non-PVL } \\ (\mathrm{n}=155)\end{array} & \begin{array}{l}\text { P-value } \\ \text { PIH }\end{array} \\ \text { GDM } & 1(12) & 33(21) & 0.529 \\ \text { PROM } & 4(25) & 59(38) & 0.295 \\ \text { Duration of PROM (hr) } & 82 \pm 67 & 170 \pm 301 & 0.565 \\ \text { Prenatal antibiotics } & 5(29) & 29(19) & 0.339 \\ \text { Duration of antibiotics (d) } & 3 \pm 4 & 6 \pm 11 & 0.681 \\ \text { Chorioamnionitis } & 12(71) & 62(40) & 0.016 \\ \text { Oligohydroamnios } & 0 & 3(2) & 1.000 \\ \text { Prenatal steroid } & 7(41) & 79(51) & 0.456\end{array}$

Values are expressed as number (\%) or mean \pm standard deviation. Abbreviations: PVL, periventricular leukomalacia; PIH, pregnancy induced hypertension; GDM, gestational diabetes mellitus; PROM, premature rupture of membrane.
었으며(PVL군, 949 $\pm 247 \mathrm{~g}$; non-PVL군, 1,068 $\pm 284 \mathrm{~g}$ ) PVL이 발생한 환아 중 가장 큰 재태주령은 $31+2$ 주, 체중 $1,320 \mathrm{~g}$ 이었다. 두 군 간 에 아프가 점수, 성별, 분만 형태는 유의한 차이가 없었다(Table 2).

\section{2. 주산기적 요인}

두 군 간의 임신성 고혈압, 임신성 당뇨, 조기 양막 파수, 양막 파 수 기간, 산모의 항생제 사용 여부, 산모의 항생제 사용 기간, 양수 과소증, 산전 스테 로이드 투여 여부는 차이가 없었다. 그러나 조직 학적 융모양막염은 PVL이 발생한 군에서 통계적으로 유의하게 많 았다 $(P<0.05)$ (Table 3).

\section{3. 출생 후 요인}

두 군 간의 신생아 호흡 곤란 증후군, 동맥관 개존증, 지속성 폐 고 혈압, 폐 기 흥, 배꼽 혈관을 포함한 중심 정맥 도관의 사용 기간 등 은 유의한 차이가 없었다. 침습적 및 비침습적 기계 환기 요법, 산소 투여 기간 등도 두 군 간에 유의한 차이는 없었다. 조발형과 지발형

Table 4. Postnatal Associated Factors of PVL in Very Low Birth Weight Infants

\begin{tabular}{|c|c|c|c|}
\hline Variable & $\begin{array}{c}\text { PVL } \\
(n=17)\end{array}$ & $\begin{array}{c}\text { Non-PVL } \\
(n=155)\end{array}$ & $P$-value \\
\hline RDS & $16(94)$ & $128(82)$ & 0.480 \\
\hline PDA & $15(88)$ & $126(81)$ & 0.740 \\
\hline PDA ligation & $1(6)$ & $10(6)$ & 1.000 \\
\hline Pulmonary hypertension & $1(6)$ & $8(5)$ & 1.000 \\
\hline Pulmonary air leak & $2(12)$ & $13(8)$ & 0.641 \\
\hline UAC duration (d) & $10 \pm 5$ & $9 \pm 4$ & 0.364 \\
\hline UVC duration (d) & $7 \pm 4$ & $7 \pm 4$ & 0.672 \\
\hline PCVC duration (d) & $44 \pm 25$ & $46 \pm 27$ & 0.864 \\
\hline Intubation duration (d) & $56 \pm 36$ & $44 \pm 40$ & 0.238 \\
\hline HFOV duration (d) & $20 \pm 21$ & $26 \pm 22$ & 0.309 \\
\hline CPAP duration $(\mathrm{d})$ & $20 \pm 15$ & $22 \pm 13$ & 0.574 \\
\hline Total ventilator duration (d) & $76 \pm 47$ & $59 \pm 47$ & 0.156 \\
\hline Duration of oxygen therapy (d) & $61 \pm 52$ & $43 \pm 50$ & 0.209 \\
\hline TPN duration (d) & $30 \pm 24$ & $35 \pm 21$ & 0.379 \\
\hline Early sepsis & $1(6)$ & $15(10)$ & 0.493 \\
\hline Sepsis & $3(18)$ & $70(45)$ & 0.023 \\
\hline Sepsis onset (d) & $19 \pm 23$ & $20 \pm 15$ & 0.952 \\
\hline Hypotension & $10(59)$ & $55(35)$ & 0.063 \\
\hline NEC & 0 & 0 & 1.000 \\
\hline
\end{tabular}

Values are expressed as number (\%) or mean \pm standard deviation. Abbreviations: PVL, periventricular leukomalacia; RDS, respiratory distress syndrome; PDA, patent ductus arteriosus; UAC, umbilical arterial catheterization; UVC, umbilical venous catheterization; PCVC, percutaneous central venous catheterization; HFOV, high frequency oscillation ventilator; CPAP, continuous positive airway pressure; TPN, total parenteral nutrition; NEC, necrotizing enterocolitis. 
을 포함한 패혈증의 빈도는 PVL이 발생한 군에서 오히려 더 낮았으 나 $(P<0.05)$, 조발형 패혈증의 빈도와 패혈증의 발병 시기는 차이가 없었다. 저혈압과 괴사성 장염의 발생 빈도는 두 군 간에 유의한 차 이가 없었다(Table 4).

\section{4. 이환율과 사망률}

기관지폐 형성 이상, 3 단계 이상의 미숙아 망막증, 수술적 치료가 필요한 미숙아 망막증, 입원 기간, 사망률의 빈도는 두 군 간에 차이 가 없었다. 그러나 3단계 이상의 뇌실 내 출혈의 발생 빈도는 PVL군 에서 유의하게 높았다 $(P<0.05)$ (Table 5).

\section{5. 위험인자}

다변량 로지스틱 회귀분석(multiple logistic regression analysis) 을 시행하였을 때, 조직학적 융모양막염(odds ratio [OR], 6.3; 95\% confidence interval [CI], 1.1-36.3; $P=0.039$ )과 3 단계 이상의 뇌실 내 출혈(OR, $16.9 ; 95 \% \mathrm{CI}, 1.9-153.1 ; P=0.012)$ 이 PVL의 유의한 위험 인자로 나타났다(Table 6).

고찰

극소 저체중출생아에서 cystic PVL의 빈도는 3\%-15\%로 ${ }^{1,9)}$ 보고하 고 있으며, 본 연구에서 2010년에서 2014년까지 극소 저체중출생아

Table 5. Comparison of Morbidity and Mortality between the Groups

\begin{tabular}{lrcc} 
Variable & $\begin{array}{c}\text { PVL } \\
(\mathrm{n}=17)\end{array}$ & $\begin{array}{c}\text { Non-PVL } \\
(\mathrm{n}=155)\end{array}$ & $P$-value \\
\hline BPD & $14(82)$ & $103(66)$ & 0.155 \\
IVH (stage $\geq 3)$ & $5(29)$ & $4(3)$ & 0.001 \\
ROP (grade $\geq 3)$ & $3(18)$ & $21(14)$ & 0.441 \\
ROP with laser therapy & $5(29)$ & $19(12)$ & 0.041 \\
Hospital day (d) & $103 \pm 58$ & $84 \pm 50$ & 0.161 \\
Mortality & $3(18)$ & $26(17)$ & 0.725 \\
\hline
\end{tabular}

Values are expressed as number (\%) or mean \pm standard deviation. Abbreviations: PVL, periventricular leukomalacia; BPD, bronchopulmonary dysplasia; IVH, intraventricular hemorrhage; ROP, retinopathy of prematurity.

Table 6. Multiple Logistic Regression Analysis of Associated Factor of Periventricular Leukomalacia

\begin{tabular}{lrcc} 
Determinants & OR & $95 \%$ CI & $P$-value \\
\hline Chorioamnionitis & 6.29 & $1.09-36.26$ & 0.039 \\
IVH (stage $\geq 3$ ) & 16.90 & $1.87-153.13$ & 0.012 \\
\hline
\end{tabular}

Abbreviations: OR, odd ratio; CI, confidence interval; IVH, intraventricular hemorrhage.
의 non-cystic PVL 및 cystic PVL의 빈도는 9.8\%였고, 비낭종성을 제 외한 cystic PVL의 빈도는 7.6\%로 외국 보고와 유사한 빈도를 나타 냈다. 국내 한국 신생아 네트워크(Korean Neonatal Network, KNN) 의 보고에 의하면 극소 저체중출생아에서 cystic PVL의 빈도는 2014 년에 8.3\% $\%^{10)}$, 2015년에 6.9\% $\%^{11)}$, 2016년에 6.7\% $\%^{12)}$ 로 2014년도에는 본 연구가 더 낮은 소견을 보이고 있으나 2015년도 이후에는 KNN 의 보고가 감소하는 추세에 있어서 본 단일기관에서의 빈도 변화에 대해서 추가적인 연구가 필요할 것으로 생각된다.

$\mathrm{PVL}$ 의 진단은 뇌 초음파가 비침습적이고 시간이나 공간에 제한 받지 않으면서 NICU에서 간단하게 검사할 수 있어 일차적으로 사용 되고 있다. PVL의 단계, ${ }^{7,}$ 는 1 주일 이상 뇌실 주위 음영 증가가 지속 되는 경우로 정의하는데 De Vries 등고도 뇌 초음파검사에서 뇌실 음 영 증가가 장기적으로 지속되는 경우에는 PVL의 범위에 속한다고 하였다. 그러나 뇌 초음파검사만으로는 뇌실 주위 음영 증가의 여부 에 대한 진단을 놓칠 수 있으므로 Inder 등'13)은 미숙아에서 백질 음 영의 이상, 백질 부피 감소 및 낭종성 변화를 정확하게 진단하기 위 해서는 뇌 MRI 검사가 필요하다고 하였다. 미만성이면서 non-cystic PVL의 발생은 cystic PVL보다 빈도가 높아서 극소 저체중출생아의 $20 \%$ 이상에서 발생한다고 하였고 ${ }^{13,14}$, Hatzidaki 등 ${ }^{15)}$ 은 재태주령 24 주에서 34 주 사이의 미숙아에서 진단된 PVL의 $37.6 \%$ 에서 비낭종 성으로 진단되었다고 하였다. 본 연구에서는 뇌 초음파에서 뇌실 주 위의 음영 증가가 1 주일 이상 지속되면서 낭종성 형태로 변화되지 않는 경우에는 퇴원 전에 뇌 MRI 검사를 시행하였고 검사에서 지속 적인 뇌실 주위 음영 증가가 보이는 경우를 1단계의 non-cystic PVL 로 확진하였다. 1 단계로 진단된 4 명의 환자들은 퇴원 전부터 재활 의학과와의 협진을 통해 재활치료의 여부와 시기를 결정하였고 퇴 원 후에도 지속적인 추적 관찰과 운동치료를 받았다. 이들 중 1 명은 재활치료 중 신생아 경련이 발병했고 강직성 양측 마비 진단을 받 았다. 대부분의 PVL의 연구는 낭종성 변화가 발생한 미숙아를 대상 으로 장기적인 예후에 대한 평가가 이루어지기 때문에 실제로 noncystic PVL로 초기부터 적극적인 추적검사와 재활치료가 필요한 극 소 저체중출생아의 다수가 누락이 될 가능성이 많을 것으로 생각된 다. 따라서 향후에는 극소 저체중출생아의 경우 뇌 초음파검사에서 non-cystic PVL이 의심된다면 뇌 MRI의 추적검사를 시행하여 진단 을 확진하고 장기적으로 신경학적 발달 검사와 재활치료가 적극적 으로 이루어져야 할 것이다.

PVL은 극소 저체중출생아에서 불량한 신경학적 예후를 일으키는 중요한 이환율의 하나로 cystic PVL을 가진 미숙아의 60\%-80\%에서 뇌성마비가 발생하는 것으로 되어 있는데 국소적인 낭종이 있는 경 우는 강직성 양측 마비, 광범위한 낭종이 있는 경우는 강직성 사지 마비의 발생 빈도가 흔하다고 되어 있다 ${ }^{14}$. 또한 non-cystic PVL을 가진 미숙아의 $16 \%$ 에서도 뇌성마비가 발생한다고 보고하고 있어 14) 이러한 신경학적 손상을 줄이기 위해서는 PVL과 연관된 위험인 
자에 노출되는 것을 예방하고 위험인자가 생겼을 때에 적절한 치료 가 이루어지는 것이 중요할 것이다. PVL의 위험인자로는 미숙아, 조 기 망막 파수와 파수 기간, 조직학적 융모양막염, 조발형 패혈증, 저 산소증, 동맥관 개존증, 뇌실 내 출혈 등 여러 인자들이 연관된 것 으로 알려져 있는데 ${ }^{3-6)}$, 본 연구에서는 조직학적 융모양막염과 3단 계 이상의 중증의 뇌실 내 출혈이 위험인자로 나타나 기존의 연구들 과 유사한 결과를 보였다. 재태주령 32주 미만인 극소 저체중출생아 를 대상으로 연구한 Chau 등 ${ }^{16}$ 과 미숙아를 대상으로 메타분석을 시 행한 Wu와 Colford ${ }^{17)}$ 는 조직학적 융모양막염이 cystic PVL과 뇌성 마비 등의 발생과 직접적인 연관성이 있다고 하였고, Resch 등 ${ }^{18)}$ 과 Denzler 등 ${ }^{19)}$ 은 재태주령 26주에서 35주 사이의 미숙아에서 cystic PVL의 위험인자로 조기 망막 파수와 조직학적 융모양막염을 보고 하였다. 본 연구에서는 조기 양막 파수와 PVL과는 통계적인 연관성 은 없었고 조기 양막 파수가 있었던 경우의 $14.6 \%$, 조기 양막 파수 가 없었던 경우의 $19.6 \%$ 에서 조직학적 융모양막염이 진단되어 조 기 양막 파수도 조직학적 융모양막염의 발생과 연관성은 없었다. 산 모의 항생제 사용은 조직학적 융모양막염이 진단된 경우 $31 \%$, 임상 적 융모양막염으로 진단된 경우 $13 \%$ 로 실제로 조직학적 융모양막 염이 진단된 경우에서 더 높은 사용 빈도를 나타냈으나 통계적인 의 미는 없었다.

Hatzidaki 등 ${ }^{15)}$ 은 뇌실 내 출혈이 PVL의 위험인자라고 보고하였 고 Kusters 등 ${ }^{3}$ 은 3 단계 이상의 중증의 뇌실 내 출혈과 cystic PVL이 유의한 연관성이 있다고 하였는데 본 연구에서도 2-3단계의 PVL이 발생한 환자의 5 명에서 3 단계의 뇌실 내 출혈이 먼저 발생한 후에 낭종성 변화로 진행되었다. 그러나 1단계의 non-cystic PVL에서는 뇌실 내 출혈이 동반된 경우가 없었기 때문에 3단계 이상의 뇌실 내 출혈은 cystic PVL의 발생에 대해서만 제한적인 위험인자가 될 수 있 는 것으로 생각된다. 그리고 3단계의 뇌실 내 출혈이 발생한 5명의 환자 중 3 명은 생후 1 주일 내, 특히 2 명은 생후 3 일에 시행한 뇌 초음 파검사에서 진단되었기에 주산기적 문제의 예방과 출생 후 조기의 처치가 적절하게 이루어지는 것이 중증의 뇌실 내 출혈과 이로 인한 PVL의 발생을 줄이기 위해 중요할 것으로 생각된다.

Yim 등 ${ }^{20)}$ 은 2015년도 국내 전국 데이터베이스에 뇌성마비로 등 록된 1 세 이상의 소아들을 대상으로 뇌성마비의 원인을 조사하였 는데, 뇌 MRI에서 PVL이 진단된 경우가 전체 환아의 $54 \%$ 로 가장 많다고 보고하였다. 또한 뇌성마비가 있는 환아들의 대부분은 미

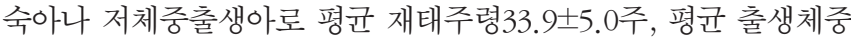
$2,165 \pm 947 \mathrm{~g}$ 이었다. 이들 중 극소 저체중출생아인 경우가 전체의 $29 \%$ 를 차지하였고, 재태주령 28주 미만의 미숙아는 $12 \%, 31$ 주 이하 의 미숙아는 전체의 $37 \%$ 의 분포를 나타냈다. 이처럼 국내의 연구에 서도 뇌성마비의 발생이 극소 저체중출생아에서 가장 많이 나타나 고 PVL과 연관성이 크기 때문에 PVL의 발생을 줄이고자 하는 전략 과 치료가 필요할 것이다.
본 연구는 단일기관의 연구로 대상 환자 수가 많지 않은 제한점 이 있으나 극소 저체중출생아에서 non-cystic PVL을 포함하여 PVL 의 발생에서 조직학적 융모양막염과 같은 주산기적 위험인자와 직 접적인 연관성을 보여줬다는 데 의미가 있을 것이다. 주산기적인 요 인의 진단과 치료는 산과 의사의 진료 지침에 따라서도 영향을 받 을 수 있음으로 극소 저체중출생아의 이환율과 신경학적 불량한 예 후를 감소시키기 위해서는 향후 산과 의사와 함께 주산기적 문제에 대해 다학적인 연구와 해결 방법을 모색하는 것이 필요할 것이다.

\section{ARTICLE INFORMATION}

\section{Ethical statement}

The study was approved by Institutional Review Board (IRB) of Inje University College of Medicine, Ilsan Paik Hospital (IRB No. 2018-06-0150). Written informed consent was obtained from all patients.

\section{Conflicts of interest}

No potential conflict of interest relevant to this article was reported.

\section{Author contributions}

Conception or design: H.A.P., J.H.H.

Acquisition, analysis, or interpretation of data: H.A.P., J.H.H.

Drafting the work or revising: H.A.P., J.H.H.

Final approval of the manuscript: J.H.H.

\section{ORCID}

Hyun A Park https://orcid.org/0000-0002-9555-8669

Jong Hee Hwang https://orcid.org/0000-0002-4510-0545

\section{Acknowledgments}

None

\section{REFERENCES}

1. Khwaja O, Volpe JJ. Pathogenesis of cerebral white matter injury of prematurity. Arch Dis Child Fetal Neonatal Ed 2008;93:F15361.

2. Blumenthal I. Periventricular leucomalacia: a review. Eur J Pediatr 2004;163:435-42.

3. Kusters CD, Chen ML, Follett PL, Dammann O. "Intraventri 
cular" hemorrhage and cystic periventricular leukomalacia in preterm infants: how are they related? J Child Neurol 2009;24: 1158-70.

4. Rocha G, Proenca E, Quintas C, Rodrigues T, Guimaraes H. Chorioamnionitis and brain damage in the preterm newborn. J Matern Fetal Neonatal Med 2007;20:745-9.

5. Herzog M, Cerar LK, Srsen TP, Verdenik I, Lucovnik M. Impact of risk factors other than prematurity on periventricular leukomalacia. A population-based matched case control study. Eur J Obstet Gynecol Reprod Biol 2015;187:57-9.

6. Al Tawil KI, El Mahdy HS, Al Rifai MT, Tamim HM, Ahmed IA, Al Saif SA. Risk factors for isolated periventricular leukomalacia. Pediatr Neurol 2012;46:149-53.

7. deVries LS, Eken P, Dubowitz LM. The spectrum ofleukomalacia using cranial ultrasound. Behav Brain Res 1992;49:1-6.

8. Volpe JJ. Neurology of the newborn. 5th ed. Philadelphia: Elsevier, 2008.

9. Counsell SJ, Allsop JM, Harrison MC, Larkman DJ, Kennea NL, Kapellou O, et al. Diffusion-weighted imaging of the brain in preterm infants with focal and diffuse white matter abnormality. Pediatrics 2003;112(1 Pt 1):1-7.

10. Korean Neonatal Network database. Very low birth weight infants in 2014 [Internet]. Seoul: KNN; c2017 [cited 2020 May 11]. Available from: http://www.knn.or.kr/index.jsp.

11. Korean Neonatal Network database. Very low birth weight infants in 2015 [Internet]. Seoul: KNN; c2017 [cited 2020 May 11]. Available from: http://www.knn.or.kr/index.jsp.

12. Korean Neonatal Network database. Very low birth weight infants in 2016 [Internet]. Seoul: KNN; c2017 [cited 2020 May 11]. Available from: http://www.knn.or.kr/index.jsp.

13. Inder TE, Wells SJ, Mogridge NB, Spencer C, Volpe JJ. Defining the nature of the cerebral abnormalities in the premature infant: a qualitative magnetic resonance imaging study. J Pediatr 2003; 143:171-9.

14. Section II: Medical care of the preterm infants. In: Malcolm WF, editor. Beyond the NICU. New York: McGraw-Hill Education, 2015.

15. Hatzidaki E, Giahnakis E, Maraka S, Korakaki E, Manoura A, Saitakis E, et al. Risk factors for periventricular leukomalacia. Acta Obstet Gynecol Scand 2009;88:110-5.

16. Chau V, McFadden DE, Poskitt KJ, Miller SP. Chorioamnionitis in the pathogenesis of brain injury in preterm infants. Clin Perinatol 2014;41:83-103.

17. $\mathrm{Wu} \mathrm{YW}$, Colford JM Jr. Chorioamnionitis as a risk factor for cerebral palsy: a meta-analysis. JAMA 2000;284:1417-24.

18. Resch B, Vollaard E, Maurer U, Haas J, Rosegger H, Muller W. Risk factors and determinants of neurodevelopmental outcome in cystic periventricular leucomalacia. Eur J Pediatr 2000;159: 663-70.

19. Denzler A, Burkhardt T, Natalucci G, Zimmermann R. Latency after preterm prelabor rupture of the membranes: increased risk for periventricular leukomalacia. J Pregnancy 2014; 2014:874984.

20. Yim SY, Yang CY, Park JH, Kim MY, Shin YB, Kang EY, et al. Korean Database of Cerebral Palsy: a report on characteristics of cerebral palsy in South Korea. Ann Rehabil Med 2017;41:638-49. 